\title{
Coxsackievirus A24 Variant Associated with Acute Haemorrhagic Conjunctivitis Cases, French Guiana, 2017
}

\author{
Antoine Enfissi $^{a} \quad$ Marie-Line Joffret $^{b, c}$ Déborah Delaune ${ }^{b, d}$ \\ Francis Delpeyroux ${ }^{b, c}$ Dominique Rousset ${ }^{a}$ Maël Bessaud ${ }^{b, c}$ \\ a Institut Pasteur de la Guyane, Cayenne, France; ${ }^{b}$ Institut Pasteur, Unité de Biologie des Virus Entériques, \\ INSERM U994, Paris, France; ' $W H O$ Collaborating Center for Enteroviruses and Viral Vaccines, Paris, France; \\ dInstitut de Recherche Biomédicale des Armées, Brétigny-sur-Orge, France
}

\section{Keywords \\ Coxsackievirus · Conjunctivitis · Enterovirus $C$ species}

\begin{abstract}
In 2017, numerous cases of acute haemorrhagic conjunctivitis $(\mathrm{AHC})$ were reported in the Caribbean and in South America. Preliminary reports identified adenoviruses and enteroviruses in some patient samples but, until now, none of the etiologic agents have been fully characterized. We report the full-length genomic sequences of 4 coxsackievirus A24 (CVA24) isolates collected from AHC patients in French Guiana during this outbreak (May and June 2017). These isolates are very closely related and belong to the genotype IV of CV-A24 variant, which consists of strains sampled worldwide during AHC outbreaks in the 2000s and 2010s. No recombination events were detected within the genomic sequences, indicating that members of this genotype have continuously circulated worldwide for more than 10 years without undergoing recombination with other enteroviruses. This unusual trait could be due to their ocular tropism that could impede genetic exchanges between these viruses and other enteroviruses, which replicate mainly in the gut.
\end{abstract}

(c) 2018 S. Karger AG, Basel (c) 2018 S. Karger AG, Basel
Acute haemorrhagic conjunctivitis (AHC) is a highly contagious disease, generally caused by a virus. Enteroviruses (EVs) and adenoviruses are the main etiologic agents of AHC $[1,2]$. In particular, coxsackievirus A24 (CV-A24, member of Enterovirus $C$ species) and enterovirus D70 (member of Enterovirus D species) have been associated with large AHC outbreaks in the past.

In 2017, large outbreaks of AHC occurred in the Caribbean and in South America. Thousands of cases were first reported in Mexico during the first 3 months of 2017 [3]. Tens of thousands of cases were subsequently reported in many other countries, including the French WestIndies, Cuba, the Turks and Caicos Islands, the Bahamas, Brazil, the Dominican Republic, Panama, Cuba, Nicaragua, Grenada, and Belize [4]. Preliminary reports of investigations performed on AHC cases in Martinique, Guadeloupe, Bonaire, Brazil, Suriname, and Cuba highlighted CV-A24 and adenoviruses in some case samples $[5,6]$, but the whole sequence of these viruses have not been published yet.

In French Guiana, the outbreak started in April 2017 [7] and finished in June or July [8], but no epidemiological data are available concerning this outbreak in this territory. As the National Reference Center for respiratory

\section{KARGER}

E-Mail karger@karger.com

www.karger.com/int
Maël Bessaud

Institut Pasteur

25, rue du Docteur Roux

FR-75015 Paris (France)

E-Mail mael.bessaud@ pasteur.fr 
infection viruses, the Virology Laboratory of the Institut Pasteur de la Guyane received clinical samples from patients with AHC to diagnose the responsible pathogens.

Samples were collected during the AHC outbreak from 4 individuals with AHC symptoms in May and June 2017 (Table 1). They lived in the region of Cayenne, the main town of French Guiana. Two patients had a clear epidemiologic link: Patient B is the brother of Patient A and they lived in the same house. Patients $C$ and $D$ had an indirect link to each other: the mother of Patient $\mathrm{D}$ reported close contact with Patient C's children.

Conjuctival swabs and saliva samples were collected with UTM Viral Transport Medium (Copan Diagnostics) and Oracol Saliva Collection System (Malvern Medical Developments), respectively. Samples were spiked with a commercial RNA extraction control (RNA extraction Control 670, Bioline) and RNA was extracted with QiaAmp Viral RNA kit (Qiagen). Extracts were screened with an in-house real-time RT-PCR assay for the detection of EVs (45 PCR cycles) that targets the $5^{\prime}$-untranslated region ( $\left.5^{\prime} \mathrm{UTR}\right)$ of the EV genome. Positive results were obtained for both kinds of samples from Patients A and $B$, while no amplification was detected in samples from Patients $C$ and D (Table 1). Saliva samples gave lower $\mathrm{Ct}$ values compared to the respective conjunctival swabs, indicating a higher amount of EV RNAs. The RTPCR assay that targets the RNA control was positive for all samples, thus validating the extraction step and the absence of RT-PCR inhibitor in samples from Patients C and D.

Because VP1 bears the major neutralization epitopes, typing of EV isolates relies on the genetic characterization of the VP1-encoding region. Extracts positive by realtime RT-PCR were used to amplify the VP1-encoding region using generic primers [9]. The corresponding amplicons were sequenced by Sanger techniques. The sequences obtained from samples of Patients A and B were 100\% identical and a BLAST analysis identified a coxsackievirus $\mathrm{A} 24$, a member of the Enterovirus $C$ species (EV-C; E-value $\left.7.10^{-147}\right)$. This result was consistent with preliminary reports based on partial sequences that identified CV-A24vs in samples from AHC patients in Martinique and Guadeloupe, Brazil, Surinam, and Cuba $[4,5]$.

Virus isolation was attempted using saliva samples of the 4 patients to inoculate HEp-2c and RD cells, 2 cell lines commonly used for EV isolation. Cytopathic effects were observed 3-5 days after inoculation on all cell monolayers, except 1: no cytopathic effect was observed in the $\mathrm{RD}$ monolayer inoculated with the sample from Patient $\mathrm{C}$ (Table 1), probably because of the lower sensitivity of RD cells to EV-Cs compared to that of HEp-2c cells [10].

Viruses were isolated from all saliva samples, including those of Patients $\mathrm{C}$ and $\mathrm{D}$ that gave negative results by molecular screening. This illustrates the interest of virus

Table 1. Characteristics of the patients and results of the laboratory investigations

\begin{tabular}{|c|c|c|c|c|c|c|c|c|c|}
\hline Patient & $\begin{array}{l}\text { Age, } \\
\text { years }\end{array}$ & Onset & Collection & \multicolumn{2}{|c|}{$\begin{array}{l}\text { 5'UTR-targeting } \\
\text { pan-enterovirus RT-PCR } \\
\text { cycle threshold }\end{array}$} & \multicolumn{2}{|c|}{$\begin{array}{l}\text { Cytopathic effect } \\
\text { on cells }\end{array}$} & $\begin{array}{l}\text { Virus } \\
\text { isolate } \\
\text { name }\end{array}$ & $\begin{array}{l}\text { GenBank } \\
\text { accession } \\
\text { No. }\end{array}$ \\
\hline A & 16 & May 16, 2017 & May 18, 2017 & 30.5 & 38.0 & Yes & Yes & B0519081 & MF419263 \\
\hline $\mathrm{D}$ & 14 & June 26, 2017 & June 26,2017 & negative & negative & Yes & Yes & B0627045 & MG557562 \\
\hline
\end{tabular}

Fig. 1. Phylogenetic trees of coxsackievirus A24 variants based on partial VP1 and partial 3C nucleotide sequences (genomic positions 2,637-2,961 and 5,456-5,965, respectively, according to Joseph numbering). The organization of the enterovirus genome is shown on the top, with the unique open reading frame and the $5^{\prime}$ and $3^{\prime}$ untranslated regions. The genomic regions used to draw the trees are shaded grey. The phylograms were constructed with the Kimura 2 parameter model for genetic distance determination and the neighbour-joining method. The percentage of successful bootstrap replicates ( 1,000 bootstrap replications) is indicated at nodes if higher than 85 . The year and country (ISO 3166-1 alpha-3 codes) of sampling are indicated, when available. The sequences of the prototype strains CV-A24 Joseph, CV-A24 DN19, and EV-C99 10636 were introduced for rooting the tree (indicated by black triangles). Black circles indicate the strains isolated in this study.

(For figure see next page.) 


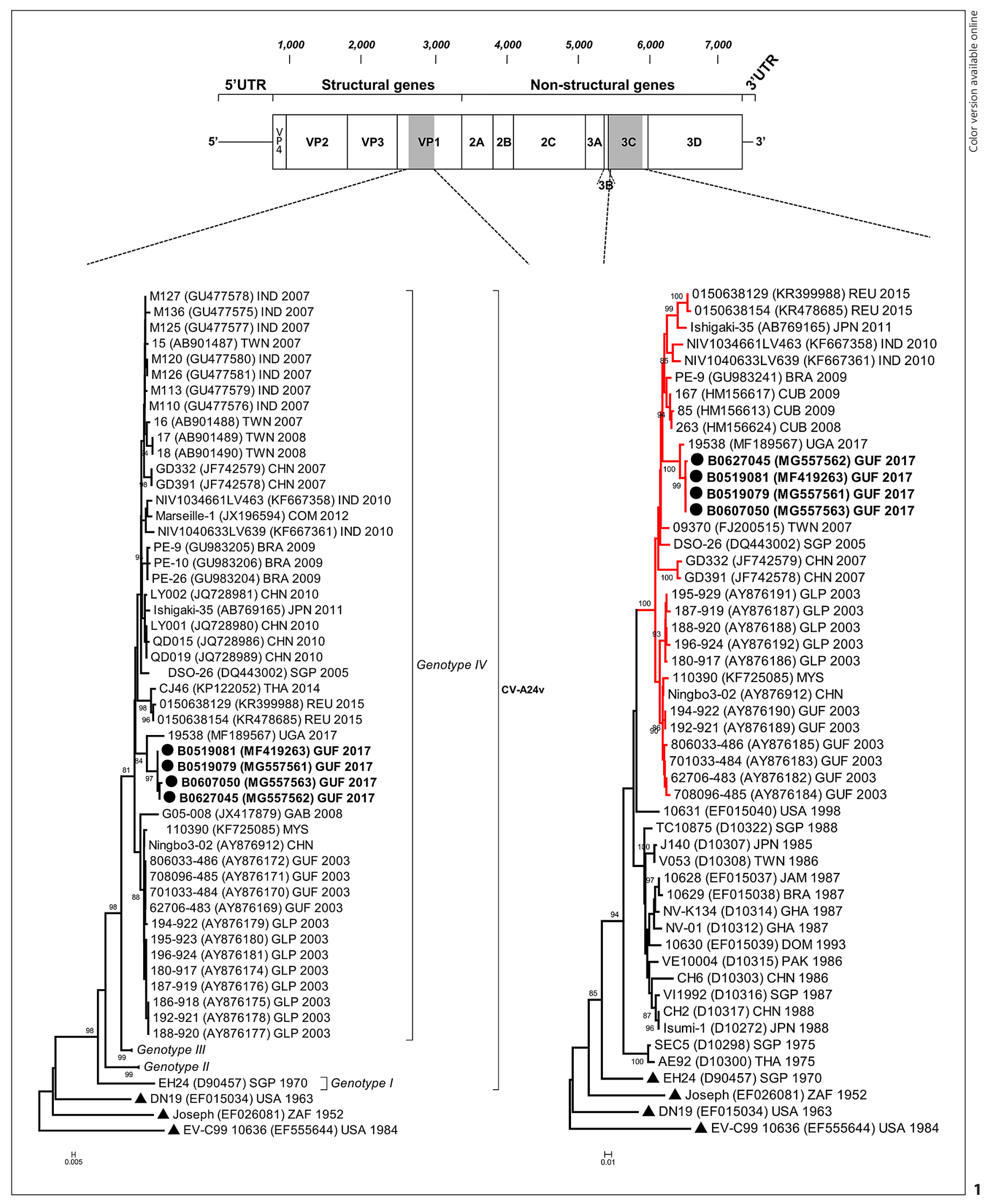

CV-A24 in French Guiana, 2017 
isolation in cells to detect viruses present in low amounts in samples.

After clarification by centrifugation, RNA was extracted from positive cell culture supernatants and the whole virus genomes were sequenced as previously described [11]. Nucleotide sequences of the 4 isolates were submitted to GenBank (MF419263 and MG557561-MG557563).

For all supernatants, sequencing gave rise to a 7,415-nucleotide-long contig that spans virtually all of the virus genome (nucleotides 21-7,433 according to CV-A24 prototype strain Joseph numbering, GenBank accession No. EF015034). For Patients A, B, and D, sequences of isolates recovered from HEp-2c supernatants were $100 \%$ identical to those recovered from the respective RD supernatants.

Isolates B0519081 and B0519079 from Patients A and $B$, respectively, were virtually identical, with only 2 nucleotide divergences ( 1 within the $2 \mathrm{~B}$-encoding region, 1 within the 3D-encoding region) and only 1 amino acid divergence within the 3D protein (online suppl. Table 1, 2; online suppl. Fig. 1; for all online suppl. material, see www. karger.com/doi/10.1159/000489339). The high sequence identity between these isolates may be due to the fact that they were recovered from 2 samples collected on the same day from Patients A and B, who are brother and sister.

The isolates from Patients $C$ and D, sampled 2 and 6 weeks later, respectively, were slightly divergent but, overall, the 4 isolates together featured a nucleotide identity $>99.7 \%$, with no more than 23 nucleotide divergences throughout the genome (online suppl. Table 1). This level of divergence is in line with that observed previously in Japan: during an AHC outbreak that occurred in Okinawa in 2011, the CV-A24v isolates collected in October featured between 21 and 30 nucleotide divergences with isolates collected 4 months before [12].

The nucleotide divergences were distributed all along the genome, both in the $5^{\prime}$ UTR and in the open reading frame (online suppl. Fig. 1). Only 6 sites featured amino acid residues that are non-conserved among the 4 isolates: 2 sites were located in the VP2, 1 in the VP1, 1 in the $2 \mathrm{C}$, and 2 in the $3 \mathrm{D}$ (online suppl. Fig. 1). By pairwise comparison, 2 isolates did not display more than 5 amino acid differences together (online suppl. Table 2).

The genetic sequences of the 4 isolates were compared to those of CV-A24 available in the public database. Based on the VP1 region, the 4 isolates belonged to the CV-A24 variant $(\mathrm{CV}-\mathrm{A} 24 \mathrm{v})$ group, the prototype strain of which is EH24 (Fig. 1). This strain was isolated during an AHC outbreak that occurred in Singapore in 1969 [13]. Because it is antigenically divergent from the $\mathrm{CV}-\mathrm{A} 24$ prototype strain Joseph, this strain was called CV-A24v. It has a marked ocular tropism due to the use of sialic acid as the cellular receptor [14]. Since the emergence of the EH24 strain, the ocular tropism of CV-A24v strains seems to have been increased by an amino acid substitution within the sialic acid-binding region of the capsid [15]. This substitution led to a tyrosine at VP1 position 250 and was recently found to enhance the ability of the virus to bind sialic acid [15]. Our 4 isolates display a tyrosine residue at this position.

Our isolates fell into the CV-A24v genotype IV [16, 17], together with strains found worldwide in the 2000s and 2010s during AHC outbreaks (Fig. 1). In particular, viruses responsible for the large AHC outbreak that took place in 2003 in the French West Indies and French Guiana also belonged to this genotype IV [18]. Our isolates appeared to be closely related to the strain 19538 (VP1 nucleotide identity $>95.6 \%$, VP1 amino acid homology $>99.3 \%$; online suppl. Table 3,4), which was sampled during a small AHC outbreak that occurred in a prison in Uganda from December 2016 to January 2017.

Within genotype IV, recent studies have defined 5 clusters of strains $[17,19]$. These clusters consist of strains that segregate together temporally, with each cluster circulating for a few years. Our isolates seem not to fall into any cluster previously observed, but this result will have to be confirmed by more extensive studies of strains involved in the 2017 outbreak and isolated elsewhere.

The 3C-encoding region is also frequently used to classify the CV-A24 isolates [20]. In this region, the 4 isolates from this study fell into a group of CV-A24v strains sampled during the 2000-2017 period (highlighted in red in Fig. 1). As previously observed in the VP1 region, they clustered with isolate 19538. Searches with an online tool dedicated to enterovirus typing [21] did not reveal any other strains particularly close to these 5 isolates.

As recombination events frequently occur among EVs in the $5^{\prime} \mathrm{UTR}$ and the non-structural part of the genome, we performed a BLAST analysis to detect such events within the genome of the 4 isolates. The nucleotide sequences corresponding to the regions $5^{\prime} \mathrm{UTR}, 2 \mathrm{~A}, 2 \mathrm{~B}, 2 \mathrm{C}$, $3 \mathrm{~A}, 3 \mathrm{~B}, 3 \mathrm{C}$, and $3 \mathrm{D}$ of the genome were extracted and used individually in separate BLAST analyses to identify, for each region, the closest sequences available in the GenBank. In all the genomic regions, the isolates from French Guiana were closer to other CV-A24vs than to any other CV-A24 or any enterovirus of another type (data not shown). These observations are consistent with a continuous evolution of the genogroup IV CV-A24v strains through genetic drift with no intertypic recombination events with other EVs [17]. The absence of recom- 
bination events between these CV-A24vs and other EVs could be due to their peculiar tropism, which probably impedes genetic exchanges with other EVs that replicate mainly in the gut.

In conclusion, we have reported the first full-length genomic sequences of CV-A24vs involved in the large AHC outbreaks that took place in South America and the Caribbean in 2017. These viruses belong to genotype IV and are closely related to CV-A24vs circulating in Uganda in January 2017. These data will help in understanding how CV-A24vs circulate and evolve. The virus isolates are available for the scientific community via the European Virus Archive (https://www.european-virus-archive. com), a non-profit organization.

\section{Acknowledgements}

The authors are indebted to W. Allan Nix (US CDC Picornavirus Lab, Atlanta) for sharing information about the Uganda strain 19538. The authors thank the staff of the Pasteur International Bioresources network (PIBnet), Plateforme de microbiologie mutualisée, Institut Pasteur, Paris. This work used the computational and storage services (TARS cluster) provided by the IT department at Institut Pasteur, Paris. This study received assistance from Investissement d'avenir grants managed by the French Agence nationale de la recherche (CEBA ANR-10-LABEX-25-01).

\section{Disclosure Statement}

The authors have no conflicts of interest to declare.

\section{References}

1 Akcay E, Carhan A, Hondur G, Tufan ZK, Demir N, Kilic S, Ensari EN, Ugurlu N, Cagil $\mathrm{N}$ : Molecular identification of viral agents associated with acute conjunctivitis: a prospective controlled study. Braz J Infect Dis 2017; 21:391-395.

-2 Jhanji V, Chan TC, Li EY, Agarwal K, Vajpayee RB: Adenoviral keratoconjunctivitis. Surv Ophthalmol 2015;60:435-443.

3 International Society for Infectious Diseases: Conjunctivitis - Mexico: (Tamaulipas). April 13, 2017. ProMED archive No. 20170413.4968931. https://www.promedmail.org/post/20170413.4968931.

4 Pan American Health Organization: Epidemiological Update: Conjunctivitis. July 25, $2017 . \quad$ http://www.paho.org/hq/index. php?option $=$ com_docman\&task $=$ doc_view \&Itemid=270\&gid $=40941$ \&lang=en.

5 Santé Publique France: Epidémie de conjonctivite virale aux Antilles. June 30, 2017. http:// invs.santepubliquefrance.fr/fr/content/ download/138210/497674/version/138151/ file/pe_conjonctivite_antilles_300617.pdf

6 Vennema H; International Society for Infectious Diseases: Conjunctivitis - Americas (05): Caribbean (Bonaire). July 4, 2017. Promed archive No. 20170704.5150640. https://www.promedmail.org/post/ 20170704.5150640.

7 Santé Publique France: Epidémie de conjonctivites virales aux Antilles. Le point épidémio. 11/2017. http://invs.santepubliquefrance.fr/ $\mathrm{fr} /$ content/download/137211/493525/version/137149/file/pe_conjonctivite_antilles_ 310517.pdf.

8 Santé Publique France: Epidémie de conjonctivites virales aux Antilles. Le point épidémio. 15/2017. http://invs.santepubliquefrance.fr/ $\mathrm{fr} /$ content/download/138482/498840/version/138152/file/pe_conjonctivite_antilles_ 130717.pdf. $\checkmark 9$ Bessaud M, Jegouic S, Joffret ML, Barge C, Balanant J, Gouandjika-Vasilache I, Delpeyroux F: Characterization of the genome of human enteroviruses: design of generic primers for amplification and sequencing of different regions of the viral genome. J Virol Methods 2008;149:277-284.

$\checkmark 10$ Bessaud M, Pillet S, Ibrahim W, Joffret ML, Pozzetto B, Delpeyroux F, Gouandjika-Vasilache I: Molecular characterization of human enteroviruses in the Central African Republic: uncovering wide diversity and identification of a new human enterovirus A71 genogroup. J Clin Microbiol 2012;50:1650-1658.

-11 Bessaud M, Sadeuh-Mba SA, Joffret ML, Razafindratsimandresy R, Polston P, Volle R, Rakoto-Andrianarivelo M, Blondel B, Njouom $\mathrm{R}$, Delpeyroux F: Whole genome sequencing of enterovirus species $\mathrm{C}$ isolates by highthroughput sequencing: development of generic primers. Front Microbiol 2016;7:1294.

12 Nidaira M, Kuba Y, Saitoh M, Taira K, Maeshiro N, Mahoe Y, Kyan H, Takara T, Okano S, Kudaka J, Yoshida H, Oishi K, Kimura H: Molecular evolution of VP3, VP1, 3C(pro) and $3 \mathrm{D}(\mathrm{pol})$ coding regions in coxsackievirus group A type 24 variant isolates from acute hemorrhagic conjunctivitis in 2011 in Okinawa, Japan. Microbiol Immunol 2014;58:227238.

13 Mirkovic RR, Schmidt NJ, Yin-Murphy M, Melnick JL: Enterovirus etiology of the 1970 Singapore epidemic of acute conjunctivitis. Intervirology 1974;4:119-127.

14 Nilsson EC, Jamshidi F, Johansson SM, Oberste MS, Arnberg N: Sialic acid is a cellular receptor for coxsackievirus A24 variant, an emerging virus with pandemic potential. J Virol 2008;82:3061-3068.

15 Baggen J, Hurdiss DL, Zocher G, Mistry N, Roberts RW, Slager JJ, Guo H, van Vliet ALW, Wahedi M, Benschop K, Duizer E, de Haan
CAM, de Vries E, Casasnovas JM, de Groot RJ, Arnberg N, Stehle T, Ranson NA, Thibaut HJ, van Kuppeveld FJM: Role of enhanced receptor engagement in the evolution of a pandemic acute hemorrhagic conjunctivitis virus. Proc Natl Acad Sci USA 2018;115:397-402.

16 Marguerite N, Brottet E, Pages F, Jaffar-Bandjee MC, Schuffenecker I, Josset L, Vilain P, Filleul L: A major outbreak of conjunctivitis caused by coxsackievirus A24, Reunion, January to April 2015. Euro Surveill 2016;21: 30271.

17 Yen YC, Chu PH, Lu PL, Lin YC, Shi YY, Chou LC, Wang CF, Lin YY, Su HJ, Lin CC, Zeng JY, Tyan YC, Ke GM, Chu PY: Phylodynamic characterization of an ocular-tropism coxsackievirus A24 variant. PLoS One 2016; 11:e0160672.

18 Dussart P, Cartet G, Huguet P, Leveque N, Hajjar C, Morvan J, Vanderkerckhove J, Ferret K, Lina B, Chomel JJ, Norder H: Outbreak of acute hemorrhagic conjunctivitis in French Guiana and West Indies caused by coxsackievirus A24 variant: phylogenetic analysis reveals Asian import. J Med Virol 2005;75:559565.

19 Zhang L, Zhao N, Huang X, Jin X, Geng X, Chan TC, Liu S: Molecular epidemiology of acute hemorrhagic conjunctivitis caused by coxsackie A type 24 variant in China, 20042014. Sci Rep 2017;7:45202.

20 Lin $\mathrm{KH}$, Chern CL, Chu PY, Chang CH, Wang HL, Sheu MM, Huang WL, Pongsuwanna Y, Yamamoto S, Yoshino S, Ishiko $\mathrm{H}$, Takeda N: Genetic analysis of recent Taiwanese isolates of a variant of coxsackievirus A24. J Med Virol 2001;64:269-274.

21 Kroneman A, Vennema H, Deforche K, v d Avoort H, Penaranda S, Oberste MS, Vinje J, Koopmans M: An automated genotyping tool for enteroviruses and noroviruses. J Clin Virol 2011;51:121-125. 